\title{
Investigating the Impact of Inflation on the Returns of Botswana's Equity Market
}

\author{
Kopano J Bolokwe \\ Botswana Stock Exchange \\ Ishmael Radikoko \\ University of Botswana
}

In this paper, we investigate the impact of inflation on Botswana's equity returns. The study tests whether Fama's (1981) proxy hypothesis holds in the context of Botswana. Using a Vector Autoregressive estimation approach, we undertake several statistical tests to validate data and generate results to investigate the underpinning hypothesis. The results show that inflation negatively impacts stock market returns in the long run. These findings carry important implications for investors, stock market analysts, scholars and policy makers and they contribute immensely to the pool of knowledge about the transmission mechanisms between the equity market and the macro economy in Botswana.

\section{INTRODUCTION}

The association between stock returns and inflation is a topic of substantial attentiveness in both empirical and theoretical spectrums as it has been widely researched across various economies. Notwithstanding, the findings and the conclusions on the subject remain puzzling. This topic finds its development and conceptualization in the Fisher (1930) hypothesis, and has transcended magnificently into a widely applied financial concept. The pool of research on the subject in developing and emerging economies has been relatively shallow in comparison to the level of interest levied on developed economies. This particularly is due to the relatively nascent stock markets in developing countries and potentially unique transmission mechanisms linking macroeconomic variables with the stock market. Further, the shallow pool of research can be attributed to the lack of readily accessible macroeconomic data from emerging markets and the size of the stock market itself, even the lack of its existence, which may not warrant sufficient motivation for research on this topic. Nevertheless, this presents an exciting opportunity to investigate the topic in the context of Botswana especially given that the empirical literature has found no clear consensus on the relationship between inflation and stock market returns.

The Fisher (1930) hypothesis, or the Fisherian hypothesis as it came to be known over time, is anchored on the notion that inflation should not affect real stock returns. In his testament, Fisher (1930) argues that real returns are a function of real factors such as time preference of investors and the productivity of capital and that these factors are independent of nominal variables such as money supply and inflation. However, several studies have established contradictory views to the Fisherian hypothesis. 
Researchers, [such Geske and Roll (1983) and Asprem (1989)], have surprisingly found opposing evidence to the Fisherian hypothesis. The consistent rejection of this hypothesis encouraged other researchers to try and explain this anomaly and a number of theories have since emerged to investigate this anomaly.

This paper intends to investigate the proxy effect hypothesis by Fama (1981) which is one of the theories explaining this anomaly. The study is conducted in the context of Botswana by investigating the impact of inflation on stock market returns generated on the Botswana Stock Exchange (BSE). Fama (1981) suggests that there is a negative relationship exists between stock market returns and inflation and to affirm this position we investigate this relationship in the context of Botswana to find out the extent to which Fama's (1981) contention holds. We use the annualized monthly change in the Consumer Price Index (CPI) as a measure of inflation and the annualized monthly change in the Domestic Company Index (DCI) as a measure of Botswana's stock market returns. The period covered spans from January 2002 to December 2014, which we believe is a good enough period to test whether the hypothesized phenomena also holds over the long-run.

This topic is of particular interest because of the importance attributed to the stock market in any country's economy. Further, the relationship between macroeconomic variables and stock market returns provides important insights as to how the linkages develop and the implications brought about by such economic linkages. The findings of a study such as this are expected to stimulate significant interest amongst the monetary policy authorities, risk management practitioners, the BSE, financial securities analysts, investors and market participants as well as to potentially influence the Government's policy towards the development of financial markets in Botswana.

The rest of the paper is arranged as follows; next we look at the literature review follow by methodology, then findings and discussion and ending with concluding remarks and recommendations.

\section{REVIEW OF RELATED LITERATURE}

The subject of this study is of great significance to capital markets participants. The impact of inflation on stock prices has been studied extensively across various markets and varying results have been obtained ranging from negative relationship, positive relationship and no relationship. A number of hypotheses that attempt to explain the relationship between inflation and stock prices have been put forth by several scholars. Bodie (1976) and (Fama \& Schwerts, 1977) found significant negative relationship between inflation changes and stock market returns in the United States (US). In his study of South African equities listed on the Johannesburg Stock Exchange (JSE), Khumalo (2013) also arrived at similar findings that inflation exerts a significant and negative impact on stock prices in South Africa. On the contrary, Pearce and Roley (1988) have found an insignificant relationship between inflation and stock market returns in the US whereas Floros (2004) found no relation between inflation and stock returns in Greece. These varying results are indeed puzzling.

What is even more puzzling is the popular contention by Fisher (1930) that stocks should offer an inflation hedge. The Fisher (1930) hypothesis purports that investors should be fully compensated for increases in overall prices of consumer goods and services through corresponding increases in the nominal stock market returns thus offering real returns to investors. Gultekin (1983) found results consistent with the Fisher hypothesis that concluded that a positive relationship exists between inflation and nominal stock returns in the United Kingdom, and this was in line with findings by Boudhouch and Richardson (1993) who studied both the US and British markets. Fama's contention, along with corroborations from other authors, has been of great interest to researchers who sought to develop theories to test this anomalous contention by Fisher (1930).

Modigliani and Cohn (1979) ${ }^{1}$ are of the view, using the inflation illusion hypothesis, that investors lack the ability to accurately compute long term growth rates of cash flows. Their argument posits that high inflation rates are correlated with high nominal interest rates, resulting in an upward trajectory on the

discount rate that investors apply to discount cash flows. Therefore, the result of discounting these cash flows at higher discount rates is a lower stock price level. The inflation illusion hypothesis thus refutes the 
Fisherian hypothesis. Feldstein (1980) on the other hand derived an alternative justification called the real after-tax hypothesis. The hypothesis explains that the manner in which the tax associated with depreciation and the way the tax levied on capital gains is treated has a resultant effect of reducing stock prices during periods of high inflation. On this basis, there exists an inverse relationship between corporate profits and inflation as a result of higher effective tax rates biased upward by higher inflation. Marshall (1992) tested this hypothesis by using inflation and asset returns data collected in a monetary endowment economy. The researcher confirmed that the inverse relationship will be less significant in periods when inflation is driven by monetary fluctuations. Quayes and Jamal (2008) also supported the real after-tax hypothesis by showing that inflation causes a proportionate decrease in the nominal value of stocks. In its empirical form, the real after-tax hypothesis also negates the Fisherian hypothesis.

An extensive work by Fama (1981) excavated the proxy hypothesis that contends that the inverse association between inflation and stock prices arises because of the change in expected economic growth that emerges as inflation increases. Fama (1981) argued that the negative stock returns -inflation relationship has its genesis in the money-demand theory and the quantity theory of money. His hypothesis argues that rising inflation rates reduce real economic activity and demand for money. Consequently, when economic activity declines, it negatively affects the future corporate profits and resultantly, the stock prices. This negative association between stock returns and inflation is accounted for by the "proxy effect" in the sense that it represents the adverse impact of inflation on real economic activity. When the effect of real output growth is controlled, Fama (1981) cautions that the statistical relationship between stock returns and inflation should disappear. Gallagher and Taylor (2002) tested the implications of the proxy hypothesis and showed that a significant and negative correlation exists between stock prices and inflation through supply shocks rather than demand shocks within the economy. Their findings prop up the proxy hypothesis as the component of inflation that is attributable to supply shocks act as a proxy for expected future movements in real activity in the economy.

In a different attempt to unpack the anomalous Fisherian hypothesis, Devereux and Yetman (2002) and Anari and Kolari (2001) formulated the risk premium hypothesis that contends that nominal discount rates impact the value of stocks negatively in the short-run because the discount rate used to discount cash flows takes into account the inflation premium and thus increases in line with inflation. This theory is related to the time-varying risk-aversion hypothesis suggested by Brandt and Wang (2003) which maintains that the risk-aversion of investors increases as inflation rises, consequently pushing up both the equity premium and the discount rate and in the process depressing stock prices.

It can be noted from the above debates by various authors that the Fisher hypothesis is indeed an anomalous hypothesis when juxtaposed with an array of theories that collectively argue for a negative inflation-stock returns relation and those that found no relation. As can be seen, a number of results have come up on this topic although most of them were focusing on developed economies, especially the United States.

Only a few studies, such as Chatrah, Ramchander \& Song (1997) in India, analyzed the inflation stock returns relationship in the developing markets with relatively nascent stock markets and potentially unique transmission mechanisms mediating real activity and monetary policies. This study will be resourceful in terms of adding to the exploration of the proxy hypothesis in the context of a developing economy such as Botswana, and will contribute to the pool of researchers such as Chatrah et al (1997), Eita (2012), and many others who have conducted the study in emerging economies.

Based on the above literature the following hypotheses were therefore formulated,

$\mathbf{H}_{1}$ : Inflation has a negative impact on stock market returns in Botswana

$\mathbf{H}_{2}$ : A long-run relationship exists between inflation and stock market returns in Botswana 
To test these hypotheses, time series data relating to Botswana's equity market as well as inflation data is utilized and a Vector Autoregressive (VAR) methodology is employed to unpack the phenomena. Details of this methodology and data used are explained next.

\section{METHODOLOGY}

This study makes use of the VAR model to model the association between inflation and stock market returns in the context of the proxy hypothesis. Relative to the OLS approach, the VAR model has the advantage that it is capable of mitigating the issue of endogeneity of the regressors as well as modelling an indirect effect between the two inputs. This study assesses the impact inflation has on stock market returns in Botswana using a 12 year data sample that covers the stock market returns on the BSE as well as the CPI published by Statistics Botswana. The study intends to test whether changes in inflation affect stock market returns in Botswana and whether the relationship is observable on the long run or short run. The study follows a quantitative methodology that comprises the definition of the VAR estimation equation and deploys various tests that explores the relationship between the two variables.

Although historical data exists in respect of both the DCI and the CPI, the entire population may not represent an appropriate sample to use for purposes of this study. As such the sample covers 144 data points for both the DCI and CPI, spanning the period January 2002 to December 2014. The DCI series was collected directly from the BSE as they maintain a database of all trading activity on the Exchange. The CPI data was obtained from Statistics Botswana who compute, maintain and publish the CPI series on a monthly basis.

The data will be analyzed mainly using a quantitative approach that involves conducting tests on EViews to estimate the VAR output. However, prior to this the two data series are checked for normality properties by assessing their descriptive statistics as depicted by the skewness, kurtosis and Jarque-Bera. A visual inspection of the data will be conducted to pin point structural points in the data set depicted by the line graph of the two series. A graphical review of the series can also help in setting the tone for the quantitative tests as it can preliminarily inform the extent to which the data series exhibit stationarity and seasonality.

The VAR model incorporates following tests for establishing the usability of the tests.

\section{Unit Root Tests or Tests for Stationarity}

The common tests to use to test for unit root or stationarity include the Augmented Dickey Fuller (ADF), Phillips-Perron (PP) and the Kwiatkowski, Phillips, Schmidt, and Shin (KPSS) unit root tests. Details on these tests are provided below.

The Augmented Dickey Fuller test is commonly used for testing first order integration, I(1) as opposed to I(0). The Phillips-Perron test will also be used to test for unit root as it is regarded as a more comprehensive test of unit root because it has an additional feature of incorporating an automatic correction to the ADF test to allow for auto correlated residuals (Brooks, 2009:330). The PP is similar to the ADF in that it also maintains a null hypothesis that the variable is non-stationary. An alternative test to the ADF and PP tests is the Kwiatkowski, Phillips, Schmidt and Shin test which has correlation correction as the PP test by allowing disturbances (errors) to be weakly dependent and heterogeneously distributed unlike the ADF where error are assumed to be independent and have a constant variance. Basically KPSS assumes that the observed time series are decomposed into the sum of the deterministic trend, random walk with zero variance, and stationary error term, Shiller and Radikoko (2014).

\section{VAR Model Estimation}

After establishing the stationarity, the next step will be to formulate and estimate the VAR model. In this study, we employ the VAR model which is commonly used for forecasting systems of interrelated time series and for analysing the dynamic impact of random variables, in this case inflation, on the system of variables which in this case is the stock market returns. A VAR model is a regression model that can be 
considered to be having characteristics of a univariate time series model and a simultaneous equations model.

We incorporate the following variables in the VAR model: CPI to represent inflation and DCI to represent stock market returns. The model use monthly annualized changes in the DCI as a representation of stock market returns and monthly annualized changes in the CPI as a representation of inflation. Inflation is conventionally measured over a period of 12 months and is reported monthly as an annual change in overall price levels of consumer goods and services.

The first stage in the estimation is the specification of the appropriate lag length $(\mathrm{k})$ of the VAR system to make the residuals uncorrelated. Following Seddighi, Lawler, \& Katos (2000:309), the final choice is based on the criteria that agree with the theory underpinning the study and all the a priori knowledge associated with the theory. For our tests we used 13 lags since the series was monthly data running on a year-on-year basis and the sample size was large and we choose the lags based on the Schwarz's Bayesian Information Criterion (SBIC) because it embodies penalty term than the Akaike Information Criterion (AIC). The lag order selection was based on the number of lags that minimize the SBIC. As such the study will base the VAR estimation on the selected lag length of 13 .

After completion of the estimation the VAR residuals are then checked for autocorrelation, normality and heteroskedasticity. Diagnostic test validates the parameter estimation results of the estimated VAR model and checks the stochastic properties of the model. The tests that are used in this study are residual normality test, serial autocorrelation test and heteroskedasticity test. The multivariate extension of the Jarque-Bera normality test compares the residuals to those from the normal distribution (Brooks, 2009: 169) and we employ this to test for normality. For autocorrelation we use the Breusch-Godfrey Serial Correlation Lagrange Multiplier (LM) Test which can be used in form of a multivariate test statistic for serial correlation and this can be up to the specified lag length. The lag length order used for this test can be the same as the one corresponding to VAR model (Harris, 1995:82). Lastly for heteroskedasticity we use the Breusch-Pagan-Godfrey test which tests that errors are both homoskedastic and independent of the regressors and that there is the absence of misspecification (Brooks, 2009: 135-139).

After performing the above residual diagnostic tests we proceed to test for causality between CPI and DCI employing the VAR model. VAR estimation can be summarized through three econometric test which are; Granger causality/block exogeneity, impulse response and variance decomposition. According to Brooks (2009), the purpose of Granger causality is to establish if there is a presence of correlation between the value of one variable and the lagged values of the other variables in the system. The Granger causality tests can additionally be used to check if a particular variable can be treated as exogenous (i.e. not affected by any variables in the model). The purpose of the impulse response function is to trace both the direct and indirect effects of a shock to one variable on the current and future values of all the endogenous variables in the VAR model. The variance decomposition shows the extent of relative importance of each random innovation in affecting the variables in the system. It determines the proportion of the variance of the forecast error for any variable in the system as is explained by innovations in other endogenous variable by separating the forecast error variance for every variable into its components.

Having discussed the relevant and possible tests, the following table summarizes the tests that will be applied to estimate the VAR output. 
TABLE 1

TESTS CONDUCTED IN ESTIMATING THE VAR MODEL

\begin{tabular}{|c|c|}
\hline Purpose of test & Test Selected \\
\hline \multirow{2}{*}{ Lag Length determination } & Akaike Information Criterion (AIC) \\
\cline { 2 - 2 } & Schwarz's Bayesian Information Criterion (SBIC) \\
\cline { 2 - 2 } & Augmented Dickey Fuller (ADF) \\
\cline { 2 - 2 } & Phillips-Perron (PP) \\
\hline Knit Root Tests & KSS \\
\hline VAR Residual Diagnostic Tests: & Residual Normality Test \\
\hline Serial Correlation & Breusch-Pagan-Godfrey Heteroskedasticity Test \\
\hline Normality & Granger Causality/ Block Exogeneity Wald Test \\
\hline Heteroskedasticity & Impulse Response \\
\hline VAR Estimation Tests: & Variance Decomposition \\
\hline Test for Causality &
\end{tabular}

\section{FINDINGS AND DISCUSSION}

Statistical description of the data is shown in Table 3 that follows. This includes presentation of means, skewness, kurtosis, Jarque-Bera statistics and their associated p-values.

TABLE 2

DESCRIPTIVE STATISTICS

\begin{tabular}{|c|c|c|}
\hline & DCI & CPI \\
\hline Observations & 156 & 156 \\
\hline Mean & 0.0008674 & 0.006400 \\
\hline Median & 0.008580 & 0.005027 \\
\hline Max & 0.138536 & 0.031749 \\
\hline Min & -0.106975 & -0.006446 \\
\hline Std. Dev. & 0.0035504 & 0.005566 \\
\hline Skewness & 0.040589 & 1.354979 \\
\hline Kurtosis & 5.664099 & 6.112466 \\
\hline Jarque-Bera & 46.17608 & 110.7036 \\
\hline Probability & 0.000000 & 0.000000 \\
\hline
\end{tabular}

The results in Table 2 above reveal that the distributional property of the data is not normal for both the DCI and CPI series The DCI (CPI) report skewness values of 0.041(1.355), kurtosis values of 5.664(6.1124) and Jarque-Bera statistics of 46.176(110.704). These results suggest that the two data series do not follow a normal distribution. Next we look at test for stationarity of the data which is also a preliminary condition to applying the VAR model. Present the result for both graphical depiction as well as results of stationary tests ( ADF, PP and the KPSS).

\section{The Informal Test for Stationarity - Graphical Analysis}

Figure 1 below is a graphical depiction of the BSE's DCI returns and the CPI from January 2002 to December 2014. The visual inspection of the graphs in Figure 1 shows that both the DCI and the CPI do not seem to trend together and the mean of the two series appear to be greater than zero. Therefore, we 
could expect the two variables to have no unit root and this provide us with preliminary information that the data might be stationary

FIGURE 1

PERFORMANCE OF THE DCI RETURNS AND CPI: 2002M01 - 2014M12

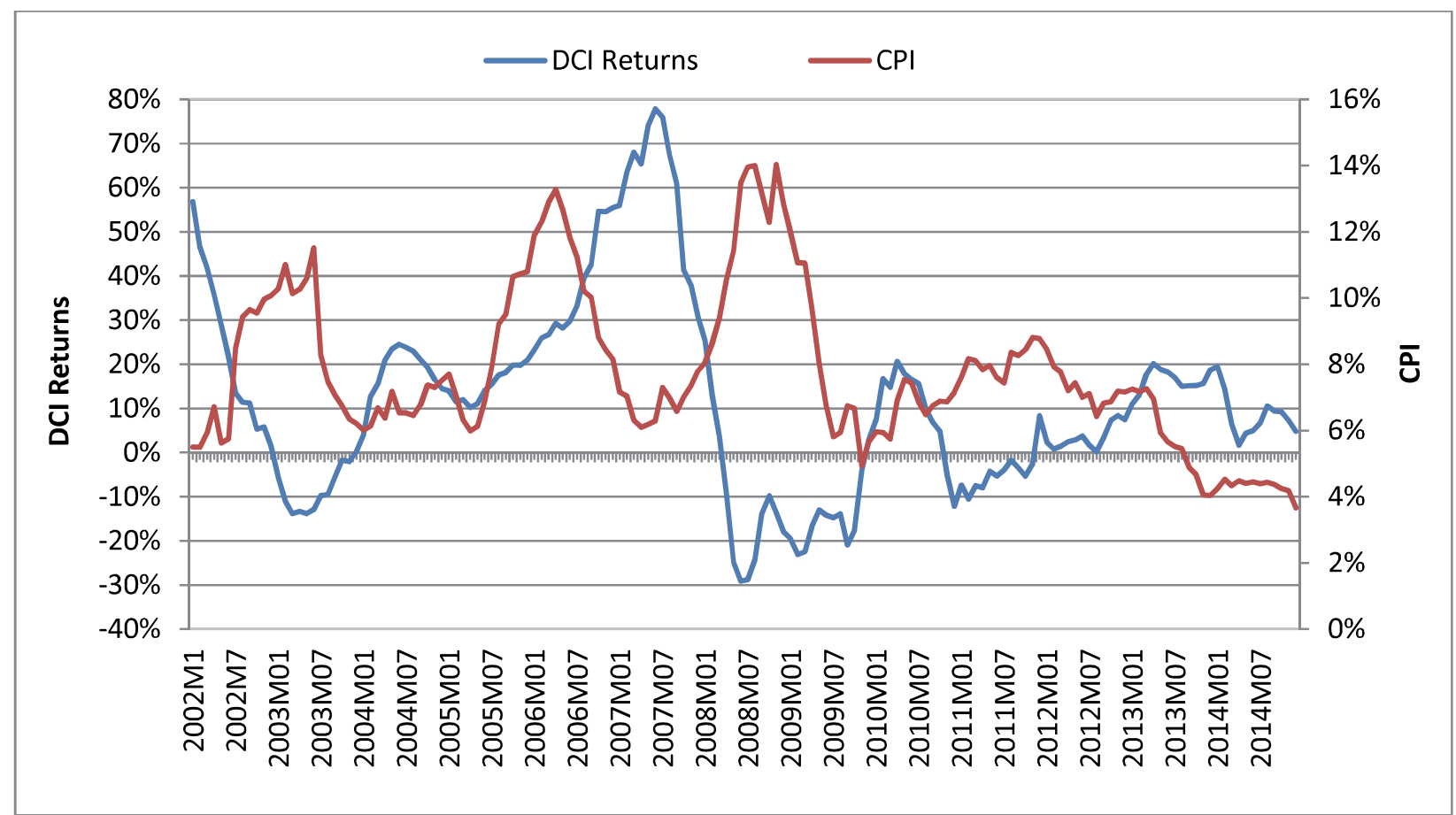

Source: BSE, SB

Having noted that the visual inspection technique is a subjective technique, formal test are required to validate the extent to which this preliminary observation and conclusion holds. In doing so, we employ unit root tests to test whether the series of the two variables exhibit unit root or whether they are stationary. The tests conducted are the ADF, PP and KPSS and the results are presented below.

Unit root test Results

TABLE 3

RESULTS OF UNIT ROOT TESTS

\begin{tabular}{|l|l|l|l|l|}
\hline & INDEX & Test & Test Statistic & Probability \\
\hline & & ADF & -7.489063 & 0 \\
\hline & DCI & PP & -7.695318 & 0 \\
\hline & & KPSS & 0.092636 & Stationary \\
\hline & & & & \\
\hline & & ADF & -8.850042 & 0 \\
\hline & CPI & PP & -8.998263 & 0 \\
\hline & & KPSS & 0.084467 & Stationary \\
\hline
\end{tabular}




\begin{tabular}{|c|c|c|c|c|c|}
\hline \multicolumn{6}{|c|}{ Critical Values } \\
\hline & $\begin{array}{l}\text { ADF \&PP (No trend \& } \\
\text { drift) }\end{array}$ & $\begin{array}{l}\text { ADF \& \& } \\
\text { (constant, } \\
\text { trend) }\end{array}$ & $\begin{array}{r}\text { PP } \\
\text { no }\end{array}$ & $\begin{array}{l}\text { KPSS ( with drift \& } \\
\text { trend) }\end{array}$ & $\begin{array}{l}\text { KPSS ( with drift } \\
\text { only) }\end{array}$ \\
\hline $1 \%$ level & -2.279967 & -3.472813 & & 0.739000 & 0.216000 \\
\hline $5 \%$ level & -1.942896 & -2.880088 & & 0.463000 & 0.146000 \\
\hline $10 \%$ level & -1.615342 & -2.576739 & & 0.347000 & 0.119000 \\
\hline
\end{tabular}

Table 3 above presents the results of units test to check whether the two series under investigation have a unit root. In all the unit root test results presented the p-values are significantly less than the 0.01 levels hence confirming that the two series under investigation are stationary. In sum the results of the unit root test tend to uniformly corroborate each other in confirming that the series do not follow a unit root process and have first order integration.

The pre-requisite for using VAR is that the series should be stationary at levels and hence the results above means that we can proceed to apply the VAR model in checking auto-regression in the two series under examination. However before we can perform VAR analysis we need to perform diagnostic test on the residuals of the two series two check different aspects of the fitted regression models and if their underlying assumptions have been met. Three tests are carried out for this purpose which includes tests for normality, correlations and heteroskedasticity. We start with the residual normality test below.

\section{Residual Diagnostic Tests}

\section{VAR Residual Normality Test}

The results of the normality (not normally distributed) test are presented in Table 4.

TABLE 4

VAR RESIDUAL NORMALITY TEST

\begin{tabular}{|l|l|l|l|}
\hline Component & Skewness & Chi-sq & Prob \\
\hline 1 & 0.084381 & 0.182752 & 0.6690 \\
\hline 2 & 0.103747 & 0.276261 & 0.5992 \\
\hline Joint & & $\mathbf{0 . 4 5 9 0 1 3}$ & $\mathbf{0 . 7 9 4 9}$ \\
\hline & & & \\
\hline Component & Kurtosis & Chi-sq & Prob \\
\hline 1 & 7.236914 & 115.1884 & 0.0000 \\
\hline 2 & 4.277665 & 10.47474 & 0.0012 \\
\hline Joint & & $\mathbf{1 2 5 . 6 6 3 1}$ & $\mathbf{0 . 0 0 0 0}$ \\
\hline & & & \\
\hline Component & Jarque-Bera & Prob & \\
\hline 1 & 115.3711 & 0.0000 & \\
\hline 2 & 10.75100 & 0.0046 & \\
\hline Joint & & $\mathbf{0 . 0 0 0 0}$ & \\
\hline
\end{tabular}

A quick look at the data shows that the residual might not be normally distributed as shown by skewness values which are higher than zero and kurtosis values in excess of 3. Furthermore the JB values far exceed the normal value of at most 6 suggesting that indeed the distributional properties of our data is not normal.

\section{Autocorrelation LM Test}

The test for autocorrelation was conducted using the Breusch-Godfrey Serial Correlation LM Test. 
TABLE 5

VAR RESIDUAL CORRELATION LM TEST

\begin{tabular}{|c|c|c|}
\hline \multirow{2}{*}{\multicolumn{3}{|c|}{$\begin{array}{l}\text { VAR Residual Serial Correlation LM Tests } \\
\text { Null Hypothesis: no serial correlation at lag order } \mathrm{h}\end{array}$}} \\
\hline & & \\
\hline \multicolumn{3}{|c|}{ Date: $14 / 04 / 16$ Time: $15: 20$} \\
\hline \multicolumn{3}{|c|}{ Sample: 1156} \\
\hline \multicolumn{3}{|c|}{ Included observations: 154} \\
\hline Lags & LM-Stat & Prob \\
\hline 1 & 1.523834 & 0.8224 \\
\hline 2 & 1.965895 & 0.742 \\
\hline 3 & 1.544697 & 0.8187 \\
\hline 4 & 3.973713 & 0.4096 \\
\hline 5 & 2.722982 & 0.6052 \\
\hline 6 & 23.21703 & 0.0001 \\
\hline 7 & 1.167706 & 0.8834 \\
\hline 8 & 1.348153 & 0.8532 \\
\hline 9 & 3.113004 & 0.5391 \\
\hline 10 & 2.311099 & 0.6787 \\
\hline 11 & 1.819895 & 0.7688 \\
\hline 12 & 15.35595 & 0.004 \\
\hline
\end{tabular}

The result of residual correlation test shown above suggest that the residual are correlated at all lags and this may suggest that the VAR model is not specified correctly as explanation for the dependent variable might not be done well by the independent variable but rather the error term which mean a further exploration of error term might be necessary. However a close look at the p-values reveals that at all lags except lag 6 and 12 the auto correlations are not statistically significant and this gives us comfort that the VAR model might not necessarily be specified wrongly.

In our last attempt to check if the underlying properties of VAR model are met, we perform the heteroskedasticity test, the results of which are discussed below 
TABLE 6

\section{HETEROSKEDASTICITY TEST}

\begin{tabular}{|c|c|c|c|c|c|}
\hline \multicolumn{3}{|l|}{ DCI } & \multicolumn{3}{|l|}{ CPI } \\
\hline \multicolumn{2}{|l|}{ F-Statistic } & 54.25610 & \multicolumn{2}{|l|}{ F-Statistic } & 60.99789 \\
\hline \multicolumn{2}{|c|}{ Obs. *R-squared } & 40.642 & \multicolumn{2}{|c|}{ Obs. *R-squared } & 44.2594 \\
\hline \multicolumn{2}{|c|}{ Prob. F (Chi-Square) } & $0.0000(0.0000)$ & \multicolumn{2}{|c|}{ Prob. F (Chi-Square) } & $0.0000(0.0000)$ \\
\hline \multicolumn{2}{|l|}{ Variable } & Prob. & Variable & t-Stat & Prob. \\
\hline $\mathrm{C}$ & 4.12733 & 0.0001 & $\mathrm{C}$ & -4.4712 & 0.0000 \\
\hline DCI & 7.36587 & 0.0000 & CPI & 7.81012 & 0.0000 \\
\hline \multicolumn{2}{|c|}{ R-Squared } & 0.26053 & \multicolumn{2}{|l|}{ R-Squared } & 0.28371 \\
\hline \multicolumn{2}{|c|}{ Durbin-Watson stat } & 0.14903 & \multicolumn{2}{|c|}{ Durbin-Watson stat } & 0.24051 \\
\hline
\end{tabular}

Generally the residual diagnostic tests seem to be consistent in declaring that there might be some model misspecification. These do not however means that we cannot continue with our tests but is just to suggest that the results of our VAR model must be treated with caution.

\section{Estimation of the VAR output}

An estimation of the VAR output encompasses investigating a causal relationship between the CPI and the DCI as the study intends to investigate the impact of inflation on stock market returns. The VAR estimation output is presented in Table 7.

TABLE 7

VAR ESTIMATION OUTPUT

\begin{tabular}{|l|l|l|}
\hline & CPI & DCI \\
\hline CPI(-1) & 1.174336 & -0.193322 \\
\hline & $(0.08022)$ & $(0.49396)$ \\
\hline & {$[14.6389]$} & {$[-0.39137]$} \\
\hline & & \\
\hline CPI(-2) & -0.222450 & 0.244472 \\
\hline & $0.08088)$ & $(0.49805)$ \\
\hline & {$[-2.75023]$} & {$[0.49086]$} \\
\hline & & \\
\hline DCI(-1) & -0.026591 & 1.463044 \\
\hline & $(0.01163)$ & $(0.07163)$ \\
\hline & {$[2.40243]$} & {$[20.4252]$} \\
\hline & & \\
\hline DCI(-2) & 0.027648 & -0.500126 \\
\hline & $(0.01151)$ & $(0.07086)$ \\
\hline & {$[2.40243]$} & {$[-7.05755]$} \\
\hline & & \\
\hline C & 0.003454 & -0.000837 \\
\hline & $0.00207)$ & $(0.01277)$ \\
\hline & {$[1.66575]$} & {$[-0.06558]$} \\
\hline & & \\
\hline R-squared & 0.921765 & 0.964346 \\
\hline
\end{tabular}


It is noted that the VAR output as presented above is a result of many parameters, and they may be difficult to interpret due to the complex interactions and feedback between the variables in the model. As a result, the interpretation of VAR model is explained by way of joint tests of restrictions. The three main tests of restrictions that summarize the VAR output as shown in table 7 above are as follows;

\section{Granger Causality}

The results of the VAR Granger Causality/Block Exogeneity Wald Tests are presented in Table 8. Taking the CPI as the dependent variable, the test indicates that the coefficient of the DCI is not significant at $5 \%$ level but is significant at $10 \%$ level of significance. This suggests that the CPI Granger causes the DCI at $10 \%$ level of significance. This implies that the appreciation of Botswana equities is affected by the general price levels of goods and service in the country as estimated by the CPI.

TABLE 8

\section{GRANGER CAUSALITY/BLOCK EXOGENEITY WALD TESTS}

\begin{tabular}{|l|l|l|}
\hline \multicolumn{4}{|l|}{ Dependent variable: CPI } \\
\hline Excluded & Chi-sq & Prob \\
\hline DCI & 5.836695 & 0.0540 \\
\hline All & 5.836695 & 0.0540 \\
\hline \multicolumn{2}{|l}{} \\
\hline Dependent variable: DCI & Prob \\
\hline Excluded & Chi-sq & 0.8571 \\
\hline DCI & 0.308307 & 0.8571 \\
\hline All & 0.308307 & \\
\hline
\end{tabular}

This result provides evidence that the lagged impact of the overall rise in price levels translates into negative returns in the stock market. However, since causality tests do not indicate the sign of the relations between variables and the duration of the effect, it is important to proceed to perform impulse responses and variance decompositions.

Impulse Response

Figure 2 represents the DCI impulse response functions to Cholesky two standard deviation innovations in CPI. Consistent with the Granger causality results, the response of the DCI to shocks in the CPI is sharply negative and is persistently so for an extended period of time, with the largest negative response taking place in the fourth quarter and rising over time. This indicates that inflation has a negative impact on stock market returns over long periods of time. 


\section{FIGURE 2 \\ IMPULSE RESPONSE RESULTS - CHOLESKY 2 STANDARD DEVIATIONS}

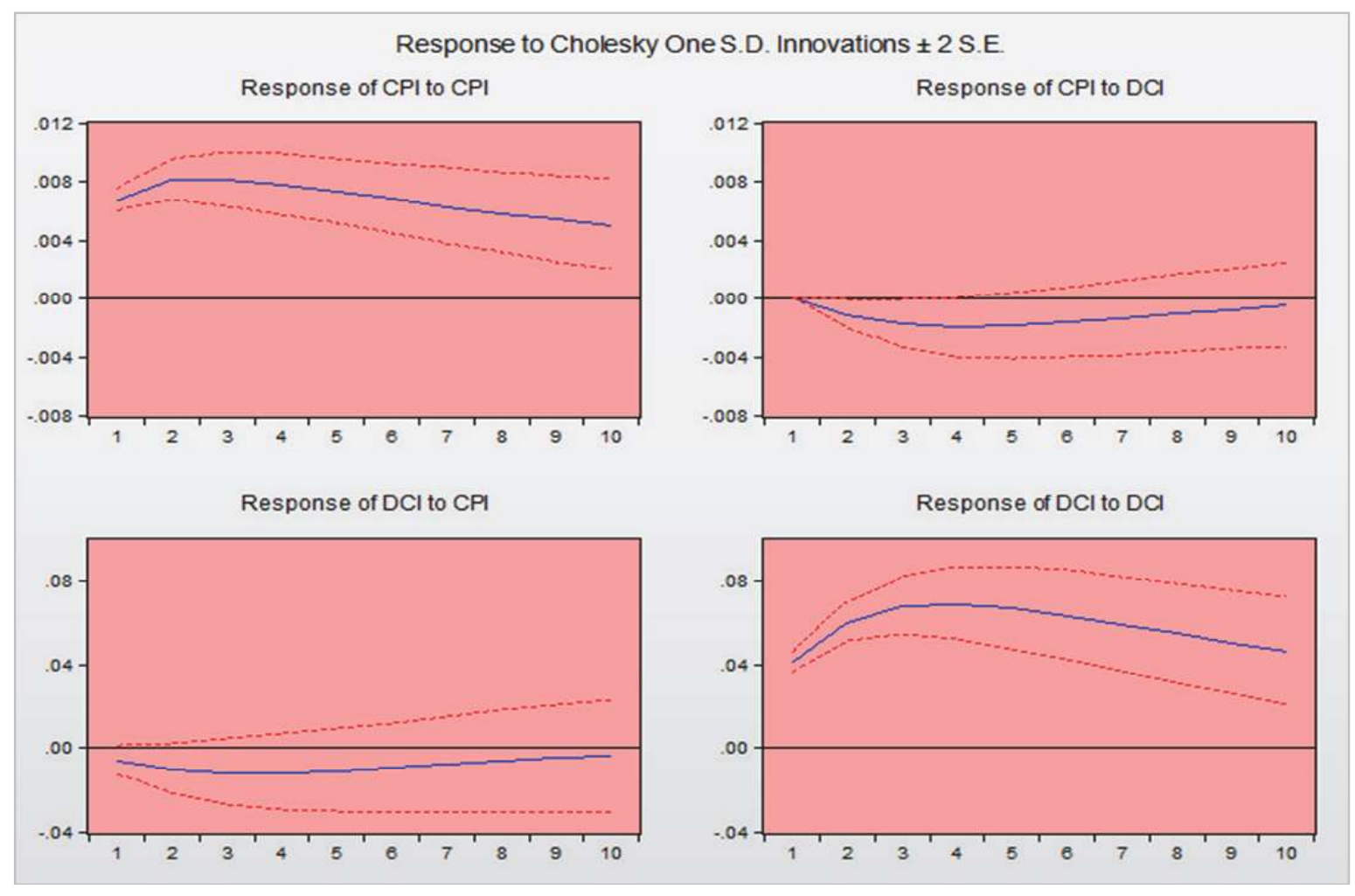

\section{Variance Decomposition}

The variance decomposition results for CPI presented in Table 9 with 2-, 4-, 6-, 8-, 10- quarter time horizon suggest that most of the forecast error variance (close to 99 percent) for CPI was accounted for by itself in the second quarter but the attribution reduced to $96 \%$ and $94 \%$ in the fourth and sixth quarter respectively before settling at $95 \%$ in the eight and tenth quarter. This analysis supports the evidence from the impulse repose that high levels of inflation, mostly double digit growth, tend to be persistent before gradually declining. Just like the variance decomposition results for CPI, the results for the DCI suggest that the DCI accounts for $98 \%$ of the forecast error variance for DCI in all the quarters. In essence, the results indicate that the CPI was not a significant factor in influencing the forecast error associated with the variance in the DCI and that the CPI can be used to confidently explain the variance of the DCI with minimal error. 
TABLE 9

VARIANCE DECOMPOSITION

\begin{tabular}{|l|l|l|l|}
\hline \multirow{2}{*}{$\begin{array}{l}\text { Variable } \\
\text { Explained }\end{array}$} & $\begin{array}{l}\text { Quarters After } \\
\text { Shock }\end{array}$ & By Innovation in (\%) & By Innovation in (\%) \\
\cline { 2 - 4 } & 2 & CPI & DCI \\
\hline \multirow{5}{*}{ CPI } & 4 & 98.997 & 1.003 \\
\cline { 2 - 4 } & 6 & 96.375 & 3.625 \\
\cline { 2 - 4 } & 8 & 94.231 & 5.769 \\
\cline { 2 - 4 } & 10 & 95.008 & 4.992 \\
\hline \multirow{5}{*}{ DCI } & & 95.010 & 4.990 \\
& 2 & 1.984 & 98.016 \\
\cline { 2 - 4 } & 4 & 1.999 & 98.001 \\
\cline { 2 - 4 } & 6 & 1.999 & 98.001 \\
\cline { 2 - 4 } & 8 & 1.999 & 98.001 \\
\cline { 2 - 4 } & 10 & 1.984 & 98.016 \\
\hline
\end{tabular}

\section{SUMMARY OF THE RESEARCH FINDINGS}

From the results and the analysis presented above we find evidence that inflation negatively impacts stock market returns in Botswana. This implies that during inflationary periods, stocks listed on the BSE register lower share prices and returns. The findings are consistent with the proxy effect by Fama (1981), implying that the proxy effect holds in Botswana. It has been noted that the negative relation holds over the long-run.

\section{CONCLUSION AND RECOMMENDATIONS}

This study deploys a VAR approach to investigate the relationship between inflation and stock market returns in Botswana. It uses the CPI to represent inflation and the DCI on the BSE to represent stock market returns. The methodology used is based on the VAR analysis, with other preliminary techniques used in order to establish the robustness of the data and the results.

The key findings from the study show that inflation negatively impacts stock market returns in Botswana. This is consistent with some of the previous researches conducted in different markets, whilst it is also contrary to some. Also the study has found that the relationship can be positive over shorter periods of time. The overall findings strongly support the proxy hypothesis by Fama (1981) and negate the Fisher (1930) hypothesis.

In closing, there is evidence that changes in inflation negatively affect stock market returns in Botswana and that the relationship is evident in the long run. Further, this study shows from the empirical results of this paper, that reviewed theoretical models and findings do provide sound explanations to the observations in the Botswana market. Accordingly, practical recommendations are made below to benefit investors, scholars, policy makers, etc, with the underpinning principle that investment diversifiation should be promoted when allocating capital and that monetary and fiscal policy actions should take into the ultimate impact of such actions on national savings. As a future piece of work, the study can be extended both in respect of the time frame and the number of independent variables investigated as well as exploring the disaggregated impact of expected and unexpected inflation on stock market returns.

The following are the recommendations based on the study: 
a) Given that the study has shown that there is a negative relationship between inflation and stock market returns in Botswana, it has been concluded therefore that stocks listed on the BSE have increased risk of poor performance during and after times of high inflation. As such investors should incorporate other assets particularly real assets such as farmland, real estate, etc, in their investment portfolios that can better diversify whilst also maximizing the risk-return potential of equities.

b) The study has highlighted the need for regulatory bodies and policy makers within financial markets to promote financial innovation. The recommendation on account of such innovation is for Government of Botswana, BoB, MFDP as well the BSE to develop inflation-linked bonds as instruments that can preserve purchasing power in times of radical inflation.

c) The study contributes to a pool of knowledge that already exists about the relationship between the two variables (and other variables not investigated herein) and these findings should be used to create more awareness amongst the investor base with a view of promoting the efficiency of capital allocation.

d) The findings from the study have profound monetary and fiscal policy implications. It has been noted in the study that higher periods of inflation emanating from certain monetary policy actions such as the devaluation of the Pula and certain Government policy actions ( such as the introduction of the alcohol levy, increase in VAT and administered prices) have had a significant bearing on the performance of listed stocks. In future, policy makers should align their policies and should look beyond the economic or societal impact of their policies and also consider the potential impacts of their policy actions on households and pension funds savings.

\section{ENDNOTES}

1. The theory was developed in an attempt to explain the depressed stock prices in the US market in the 1960s and 1970's.

\section{REFERENCES}

Anari, A. \& Kolari, J. (2001). Stock prices and inflation. Journal of Financial Research, 24, 587-602

Asprem, M. (1989). Stock price, asset portfolio and macroeconomic variables in ten European countries. Journal of Banking and Finance, Vol. 13, 589-612

Bank of Botswana. (n.d.) Annual Reports.

Bodie, Z. (1976). Common Stocks as a hedge against inflation. Journal of Finance, 459-470.

Botswana Stock Exchange. (n.d). Annual Reports.

Boudhouch, J. \& Richardson, M. (1993). Stock retums and inflation: A long-horizon perspective. American Economic Review, 8, 1346-1355.

Brandt, M.W. \& Wang, L. (2003). Time-varying risk aversion and unexpected inflation. Journal of Monetary Economics, 50, 1457-1498

Chami, R., Cosimano, T.F. \& Fullerkamp, C. (1991). The stock market channel of monetary policy. IMF working paper, No. 22

Chatrath, A., Ramchander, S. \& Song, F. (1997). Stock prices, inflation and output. Applied Financial Economics, 7, 439-445

Devereux, M.B. \& Yetman, J. (2003). Menu costs and the long-run output-inflation trade-off. Economics Letters, 76, 95-100

Eita, J. H. (2012). Modelling macroenomic determinants of stock market prices" Evidence from Namibia. The Journal of Applied Business Research, 28 (5).

Fama, E. \& Schwerts, G.W. (1977). Stock Prices and Inflation. The Journal of Finance, 115-146.

Fama, E.F. (1981). Stock returns, Real Activity, Inflation and Money. American Economic Review, $5,545-565$.

Feldstein, M. (1980). Inflation and the Stock Market. American Economic Review, 839-847. 
Fisher, I. (1930). The theory of interest. Macmillan. New York.

Gallagher, L.A. \& Taylor, M.P. (2002). The stock return-inflation puzzle revisited. Economics Letters, $75,147-156$

Geske, R. \& Roll, R. (1983). The Monetary and fiscal linkage between stock returns and inflation. Journal of Finance 38, 1-33.

Gultekin, N. B. (1983). Stock market Returns and Inflation: Evidence from other countries. Journal of Finance, 49-65.

Harris, R. (1995). Using cointegration analysis in econometric modelling. Harlow-Essex: Prentice Hall.

Khumalo, J. (2013). Inflation and Stock Prices Interactions in South Africa: VAR Analysis. International Journal of Economics and Finance Studies, 5 (2),215-226.

Marshal, D. A. (1992). Inflation and Asset Returns in a Monetary Economy. Journal of Finance, Vol. 47, No. 4, 1315-1342.

Modigliani, F. \& Cohn, R.A. (1979). Inflation, rational valuation and the market. Financial Analysts Journal, 35, 28.

Pearce, D.K. \& Roley, V.V. (1988). Firm characteristics, unanticipated inflation, and stock returns. Journal of Finance. American Finance Association, Vol 34 (4), 956-981

Quayes,S. \& Jamal, A. (2008). Does inflation affect stock prices? Applied Ecomonics Letters. Vol. 15, 767-769

Shiller, I. \& Radikoko, I. (2014). Fuzzy Liability Driven Pension Fund Management. Journal of Accounting and Finance. Vol 14 (1), 23-35

Seddighi,H., Lawler, A., \& Katos , A. (2000). Econometrics; A Practical Approach. New York: Routledge. 